\title{
Inhalt des vierten Bandes
}

$\S 1$. Atome mit 2 Elektronen .................. 4

§2. Störungstheorie zeitunabhängiger Systeme. Stoßvorgänge 19

§ 3. Der Eigendrehimpuls der atomaren Teilchen ........ 46

$\S 4$. Der Elektronenspin in der Wellenmechanik ......... 72

$\S 5$. Moleküle $\ldots \ldots \ldots \ldots \ldots \ldots \ldots \ldots \ldots \ldots \ldots \ldots . \ldots \ldots$

§ 6. Zeitabhängige Störung, Lichtstreuung, Photoeffekt ... 127

$\S 7$. Diracs Theorie des Elektrons ................ 137

Register zu Band IV ......................... 164 